BLS 35, No 1 2009. DOI: http://dx.doi.org/10.3765/bls.v35i1.3602

(published by the Berkeley Linguistics Society and the Linguistic Society of America)

\title{
Single and Double Modal Syntax: A Unified Account
}

\author{
MINTA ELSMAN and STANLEY DUBINSKY \\ University of South Carolina
}

\section{Introduction}

Double modal constructions (DMCs) such as I might could go occur in Southern and African American English. They are a challenge to traditional analyses that treat all modals as tensed and allow only one tensed element per clause. Previous analyses of DMCs thus treat only one of the modals as tensed, or treat DMs as single lexical units, and fail to account for the fact that tense-related processes apply variously to either modal, or to both. We argue that DMs consist of a P(OLARITY)-modal (e.g., might), which requires sentential scope at LF, and a Vmodal (e.g., could), which undergoes overt $\mathrm{V} \rightarrow \mathrm{T}$ movement when tensed. Either may bear tense. When a tensed V-modal (could) selects an untensed P-modal (might), the latter left-adjoins to the former, forming a complex V-head ([v[PoL might][vcould]]). This complex V-head moves to T, simultaneously satisfying the overt movement required by the $\mathrm{V}$-modal, and bringing the P-modal to a position from which it can achieve sentential scope. In this construction, tenserelated processes affect the V-head (could) or the complex V-head (might could), but not the P-modal (might) alone. When a tensed P-modal selects a V-modal, tense-related processes affect the former; the latter remains in-situ.

\section{DM Syntactic Patterns and Previous Analyses}

In DM varieties, DMCs (1a) occur alongside single modal constructions (SMCs) (1b). A DMC's semantic interpretation as one where the first expresses epistemic meaning (possibility, probability, or certainty) and the second conveys root meaning (ability, volition, or advisability) as in (2) (Nagle 1994, Marrano 1998):

(1) a. We might should go in.

[Mishoe 1991]

b. We should go in.

(2) a. Brian might can visit her.

'It is possible that Brian is able to visit her.'

[Turner 1981:30]

b. He must wouldn't steal.

'Certainly he doesn't have the inclination to steal.' 


\section{Minta Elsman and Stanley Dubinsky}

While the semantic interpretations of DMCs are largely uncontroversial, their syntax has been debated for some time and subjected to a variety of analyses.

Traditional analyses of English modal structure assume that modals are always tensed, due their lack of nonfinite forms (3a), and their complementary distribution with tense markers (3b).

(3) a. *Abelard seems to should work harder.

b. Abelard should work $(* s)$ harder.

Since English allows only one tensed element per clause, only one of the modals in DMC such as (1a) above can bear tense. Previous analyses of DMCs thus argue either that they involve one "true" tensed modal and one untensed, non-modal element, or that the entire DM bears tense as a single unit. However, these analyses cannot explain the distribution of the modals in (4-8).

(4) Aspectual Agreement:

a. He may could've been killed.

b. He might coulda been killed.

c. *He might can've been killed.

[Di Paolo 1986]

(5) Aspectual Affixation:

a. We might could've overlooked something.

[Mishoe 1991]

b. He mighta should've gotten home by now.

[Di Paolo 1989]

c. *She mighta could done it.

(6) Distribution of Negation:

a. I was afraid you might couldn't find it [this address].

b. He might not couldn't refuse.

c. I might not could understand you.

[Di Paolo 1989]

(7) Subject-Auxiliary Inversion (SAI):

a. Should we might cancel the trip?

[Mishoe 1991]

b. Might can you do this later?

[Boertien 1986]

c. * Might you could ... ?

[Battistella 1995]

(8) Placement of Sentential Adverbs:

a. You might could possibly help me, I don't know. [Mishoe 1991]

b. I've seen ones that might possibly could be flowers. [Di Paolo 1989]

Analyses that treat the first modal as tensed claim that the second modal is a nonfinite modal (Marrano 1998) or aspectual (Van Gelderen 2003) head. This is contradicted by the second modal's ability to participate independently in tenserelated processes shown in (4a), (5a), (6a), and (7a). Others claim that the second modal bears tense, while the first is an untensed modal determiner (Turner 1981) or an adverbial adjunct (Battistella 1995). This is counter-exemplified by the first modal's ability to independently precede negation (6c) and sentential adverbs (8b). More recent analyses contend that the second modal is tensed, while the first 
modal appears as either an untensed modal head or an adverbial specifier, depending on either the dialect (Close 2004) or syntactic context (Ellison 2007). ${ }^{1}$ Such analyses allow the processes in (4-8) to apply to either modal, but fail to account for the inversion of both modals as a unit (7b), and the apparent aspectual and negative "agreement" between modals in (4b), (5b), and (6b).

Alongside accounts that treat DMC constituent modals as categorically and syntactically distinct, there are analyses that claim that the modals form a single unit. Di Paolo (1989) contends that the entire DM bears tense as a single, syntactically non-compositional unit, a view that is challenged by the separability of the modals in $(6 \mathrm{c}, 7 \mathrm{a}, 8 \mathrm{~b})$. Other "single-unit" analyses propose that DMs are complex heads composed of two syntactically discreet constituent V- (Boertien 1986) or Mod(al)- heads (Mufwene 1994). However, these analyses fail to explain the existence of constructions in which a clearly non-auxiliary constituent intervenes between the two modals that supposedly form a single, complex head (6c, 8b).

The data in (4-8), taken altogether, present a picture not heretofore observed in any previous analysis, and clearly reveal the precise constraints on the application of tense-related processes to the constituent modals. What these data show is that such processes apply either to the second modal alone (4a-7a), or to the first and second modal together (4-7b), but not to the first modal alone, with the exception of the placement of negation (7c) and sentential adverbs (8b).

The table in (9) compares analyses of this construction that have appeared in the generative literature, grouping them on the basis of how DMs are inserted into the derivation, and where tense is claimed to reside in the DM configuration. The table also lists patterns, taken from (4-8), that each analysis cannot account for.

The pattern each of these analyses fails to capture, and which has not been observed in previous accounts, is the asymmetry in the application of tenserelated processes to the constituent modals of the DM. Stepping back to the data at hand, we can make several general observations. For one thing, the second modal in a DMC can independently undergo tense-related processes (4-8a). Furthermore, the second modal is typically could, can, would, should, or will (Mishoe 1991; Nagle 1994). In contrast, the first modal in a DMC does not undergo tense-related processes independently (4c), (5c), and (7c), except as regards the placement of negation and sentential adverbs (6c) and (8b). Also, the first modal is always might, may, or must (Turner 1981, Nagle 1994). Section 2 presents arguments for separating this group of modals from the rest. Section 3 presents an analysis, based on this distinction, that accounts for the DMC data.

\footnotetext{
${ }^{1}$ Ellison argues (88-90) that the first modal is merged as a specifier in interrogative contexts (8a), where analyzing both modals as heads leads to a violation of the head movement constraint by the inversion of could over might. He insists that even when merged as a specifier, the first modal maintains it modal status, but he weakens this claim by equating the specifier position of the first modal to those posited for IP adverbs in Cinque's (1999) hierarchy (Ellison: 66-67,88).
} 
Minta Elsman and Stanley Dubinsky

(9) Comparison of previous analyses of DMs

\begin{tabular}{|l|l|l|l|}
\hline Analysis & $\begin{array}{l}\text { Structural } \\
\text { Relationship }\end{array}$ & $\begin{array}{l}\text { Location of } \\
\text { Tense }\end{array}$ & Counterevidence \\
\hline Di Paolo 1986 & $\begin{array}{l}\text { single lexical } \\
\text { unit }\end{array}$ & $\begin{array}{l}\text { DM as a } \\
\text { unit }\end{array}$ & $\begin{array}{l}\text { Could you might go? } \\
\text { He might not could go. }\end{array}$ \\
\hline $\begin{array}{l}\text { Marrano 1998 } \\
\text { Van Gelderen 2003 }\end{array}$ & $\begin{array}{l}\text { distinct } \\
\text { constituents }\end{array}$ & $1^{\text {st }}$ modal & $\begin{array}{l}\text { Could you might go? } \\
\text { He might couldn't go. }\end{array}$ \\
\hline $\begin{array}{l}\text { Turner 1981 } \\
\text { Battistella 1995 }\end{array}$ & $\begin{array}{l}\text { distinct } \\
\text { constituents }\end{array}$ & $2^{\text {nd } \text { modal }}$ & He might not could go. \\
\hline $\begin{array}{l}\text { Ellise 2004 } 2006 \\
\text { distinct } \\
\text { constituents }\end{array}$ & $\begin{array}{l}\text { depends on } \\
\text { dialect or } \\
\text { context }\end{array}$ & $\begin{array}{l}\text { Might could you go? } \\
\text { He mighta coulda gone. }\end{array}$ \\
\hline $\begin{array}{l}\text { Boertien 1986 } \\
\text { Mufwene 1994 }\end{array}$ & complex head & $\begin{array}{l}2^{\text {nd }} \text { modal } \\
\text { both }\end{array}$ & $\begin{array}{l}\text { You might possibly } \\
\text { could go. }\end{array}$ \\
\hline
\end{tabular}

\section{Modals, VP and PoL(arity)P}

In discussing the asymmetry between the first and second modals in DMCs, we note that the first modal is always might, may, or must, while the second is can, could, would, should, or will. While this division between the members of the modal auxiliary category at first seems relevant only to the analysis of DMCs, an examination of the behavior of epistemic might, may, and must in American English reveals that even in SMCs, they can be distinguished from other modal auxiliaries. This leads first to a re-categorization of modal auxiliaries, and then to a unified analysis of DMCs and SMCs. In what follows, we illustrate exceptional behaviors of epistemic might, may, and must in American English, and propose a new categorization of modal auxiliaries that accounts for their unique properties.

\subsection{Distinguishing Properties of Epistemic might, may, and must}

English modals are often categorized as auxiliary heads due in part to their ability to undergo subject-auxiliary inversion (SAI) (e.g., Brewer 1989), as illustrated in (10). However, in American English, not all modal auxiliaries share this property. As McDowell (1987) observes, inversion of epistemic may and must in yes-no questions is ungrammatical, and inversion of epistemic might is marginal (11).

(10) a. Can/may Cindy finish the project early?

b. Would/should Jeff take out a loan?

c. Will it rain tomorrow?

d. Could there be a mouse in the wall?

e. Must I write the whole paper by myself? 
(11) a. *May/must it be difficult to live in the Sahara?

b. ?Might it be raining out?

These facts suggest that epistemic might, may and must in American English SMCs are subject to a constraint that does not apply to other modal auxiliaries. The constraint is also active in DMCs. As noted in (7c), the first modal in a DMC, always epistemic might, may, or must, never undergoes SAI alone in YNQs.

McDowell (1987) observes an important semantic contrast between epistemic might, may, and must and all other modals. She notes that most modal auxiliaries contribute propositional content to assertions, such that the proposition asserted by a modal sentence (12a), is not identical to the proposition asserted by its nonmodal counterpart, (12b). This can be shown by the fact that it is possible to both assert the modal proposition and deny its non-modal-counterpart without any contradiction arising, as in (12c). Importantly, McDowell's observation holds regardless of whether the modal has a root (12) or epistemic (13) interpretation.

a. John could run the marathon.

b. John runs the marathon.

c. John could run the marathon, but he doesn't run the marathon.

(13) This test could be difficult, but it isn't difficult.

In contrast with other modals, McDowell claims that epistemic might, may, and must contribute no propositional content, arguing that the propositional content of a sentence containing one of these modals (14a) is identical to the propositional content of its non-modal counterpart (14b). This is demonstrated by the fact that assertion of (14a) followed by the denial of (14b) yields a contradiction (14c).

a. This test may be difficult.

b. This test is difficult.

c. \#This test might/may be difficult, but it isn't difficult.

\subsection{Distilling Two Categories of Modals}

Summarizing first the status in American English of can/could, will/would, should, and non-epistemic may and must, we have seen that they undergo SAI and add propositional content to the sentence. Furthermore, these modals can assign subject $\theta$-roles under some readings (Barbiers 2002), as in (15). For these reasons, we take the simplest approach to these and categorize them as verbs ("Vmodals") that undergo overt $\mathrm{V} \rightarrow \mathrm{T}$ movement to check tense, as shown in (16).

(15) a. Mirya can (has the ability to) outrun Varden.

b. Josh won't (refuses to) come out of his room.

c. Erishka should (is advised to) study harder.

We should go in.

[тр We should $\mathbf{1}_{\mathbf{1}}$ [vP $\mathbf{t}_{\mathbf{1}}$ [vP go in]]] 


\section{Minta Elsman and Stanley Dubinsky}

So what of epistemic might, may, and must? In contrast with the other modals above, they do not undergo SAI, do not add propositional content, and never assign $\theta$-roles. These facts all lead us to want to distinguish them from true verbs.

McDowell (1987) is the first to propose a categorical distinction between epistemic might, may, must and all other modal auxiliaries. In her analysis, these three are "truth-conditional operators" ranging over propositions. This classification accords with traditional descriptions of epistemic modals as indicators of speaker certainty about a proposition's truth (e.g., Brewer 1989). (17) shows that epistemic might and must correlate with doubt and certainty, respectively, regarding the truth of a proposition. Since these modals surface inside the propositions whose truth conditions they modify, McDowell posits that they move at LF to the left periphery, where they scope over the sentential proposition as in (18).

a. Jeff might be in the library (but I doubt it / \#and I'm sure he is).

b. Jeff must be in the library. (I'm almost certain that's where he said he was going. / \#I doubt he's there.)

My luggage may be on the plane.

[CР $\mathbf{m a y}_{1}\left[\mathrm{TP}\right.$ my luggage $\mathbf{t}_{\mathbf{1}}[\mathrm{VP}$ be on the plane $\left.\left.]\right]\right]=\mathrm{LF}$

It is notable that epistemic might, may, and must behave similarly to sentential negation, which has also been claimed to move at LF for scope (Butler 2003, Davis and Gillon 2004) (19a), and which cannot independently undergo SAI (19b):

(19) a. My luggage is not on the plane.

[CP not $_{1}$ [TP my luggage is 2 [NEGP $\mathbf{t}_{1}\left[\mathrm{VP}_{2}\right.$ on the plane $\left.\left.\left.]\right]\right]\right]=\mathrm{LF}$

b. *Not my luggage is on the plane?

The similarities noted here between epistemic might, may and must and sentential negation motivate the assignment of these elements to a single category. Following Cormack and Smith 2002, we label this category POL(arity) (referring to modals in this category as "P-modals"), and situate it between TP and VP, as in (20). Under this analysis, P-modals differ from negation in that the former bear tense, while the latter do not, as indicated by their relative compatibility with independently tensed verbs (21). Although they bear tense, P-modals do not undergo SAI since they are not verbs. Rather, they move only at LF, moving from PoLP, through $\mathrm{T}$ (checking tense), and then into $\mathrm{CP}$, as in (22). ${ }^{2}$

\footnotetext{
${ }^{2}$ We remain agnostic as to the exact position of the P-modal in the left periphery; what is crucial here is the fact that the P-modal is only interpretable from a position above TP. In this and subsequent diagrams, CP is a generic label for an unspecified left-peripheral projection.
} 
(20) [TP my luggage is $s_{1}$ [PoLP not [ $\mathrm{VP}_{1}$ on the plane]]]]

(21) a. *My luggage might/may/must is on the plane

b. My luggage is not on the plane.

a. [CP [TP my luggage $\mathrm{T}$ [PoLP must [vp be on the plane]]]] = PF

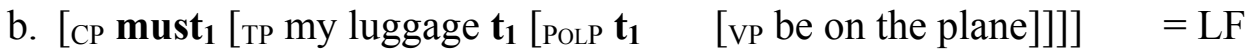

\section{DMCs as "Adjunction-Driven" Structures}

Returning to DMCs, note that the first modal in a DMC is always a P-modal (might, may or must), while the second is always a V-modal (can, could, would, should, will). Adopting Cormack and Smith's (2002) placement of POLP for the analysis of DMCs, one might propose for (1a) the structure given in (23). However, recall that in $(5 \mathrm{a}, 6 \mathrm{a}, 7 \mathrm{a})$ the second modal shows tense-like behavior. (23) fails to predict this, since the second modal (the V-modal should), being separated from $\mathrm{T}$ by the P-modal might, cannot interact with or move to $\mathrm{T}$.

(23) [tr we T [polp might [vp should [vp go in] ]]]

Given that the second modal (the V-modal) typically displays tense-like behavior in DMCs, we propose the analysis in (24), wherein the first modal (the P-modal might) is inserted into a position that is lower than that of the second. In (24), the complement of T is the VP headed by should, the complement of should is a POLP headed by might, and the complement of might is a VP headed by go.

$$
\text { [TP we T [vP should [polp might [vP go in ]]] (before spell-out) [=(1a)] }
$$

While this structure does not reflect the overt linear order of the modals, when the inherent properties of the modals are taken into account, it leads straightforwardly to an explanation of the DMC patterns observed in (4-8).

Per the analysis in 3.2, the tensed V-modal should in (24) moves to T by spellout to check tense, while the P-modal might moves to CP at LF for interpretation. If the tensed V-modal moved alone to $\mathrm{T}$ at syntax, then movement of the P-modal might would be blocked by the Head Movement Constraint (Travis 1984). With might stranded in an uninterpretable position the derivation in (25) crashes.

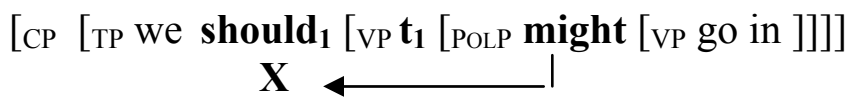

To avoid being stranded, the POL-head might must move out of POLP and adjoin to should, prior to the movement of should to T. The result of this adjunction, illustrated in (26), is a complex DM V-head might should. Since the V-head should must move to $\mathrm{T}$ in syntax, the adjunction must occur prior to spell-out. Admittedly, this movement violates LAST RESORT, since P-modals do not normally move until LF, but it does save the derivation from crashing. 


\section{Minta Elsman and Stanley Dubinsky}

[те we T [vp [v might $\mathbf{1}_{\mathbf{1}}$ [v should]] [POLP $\mathbf{t}_{\mathbf{1}}$ [vP go in ]]]]

[STEP 1]

[тр we [v might ${ }_{1}$ [v should] $]_{2}$ [VP $\mathbf{t}_{2}$ [РоLP $\mathbf{t}_{1}$ [VP go in ]]]]

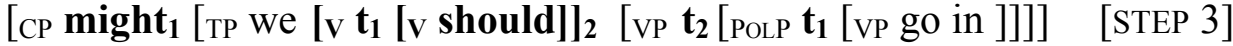

The adjunction in STEP 1 yields the surface order, and produces a structure that allows both modals to undergo their required movements. In STEP 2, the complex head (might should) moves to T, enabling the V-modal could to check tense at spell-out. Once the entire DM V-head is in T, nothing intervenes between the Pmodal and the left periphery, leaving the P-modal free to move to CP at LF (STEP 3). Section 4 shows how this "adjunction-driven" analysis succeeds in predicting the asymmetrical application of tense-related processes to the modals in the DMC.

\section{Accounting for the DM Patterns}

As observed in section 1, tense-related processes apply to the second modal alone, the first and second modal together, but not to the first modal alone. The present analysis accounts for this by positing that the DMC consists of two V-heads to which tense-related processes can apply: the simple V-modal head (27a) or the complex adjunction structure headed by the V-modal could (27b). Tense-related processes cannot apply to the first modal alone, $(27 \mathrm{c})$, since it is not a tensed Vhead. Let us see next how this hypothesis accounts for the data.
a. [v [PoL might] [v could]]
b. [v [PoL might] [v could]]
c. *[v [PoL might] [v could] $]$

Perfective've/a is an aspectual head requiring aspectual agreement (past-tense marking) on the head of its VP complement (DM V-head). This requirement is satisfied by the V-head or the complex DM V-head, but not by the P-modal alone.

a. He may could've been killed. $\ldots\left[\right.$ AsPP $^{\prime} \mathrm{ve}_{[+\mathrm{PERF}]}\left[\mathrm{vP}\left[\mathrm{v}\right.\right.$ may $\left._{1}[\mathrm{v} \text { could }]_{[+\mathrm{PERF}]}\right]\left[\mathrm{PoLP}_{1} \mathrm{t}_{1}\right.$ been killed]]]

b. He might coulda been killed.

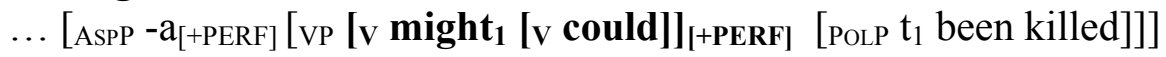

c. *He might can've been killed. ... [AsPP ${ }^{\prime v} e_{[+ \text {PERF }]}\left[\mathrm{vP}\left[\mathrm{v}\right.\right.$ might $_{1[+ \text { PERF }]}[\mathrm{v}$ can $\left.]\right]\left[\right.$ PoLP $_{1} \mathrm{t}_{1}$ been killed] $\left.]\right]$

Both (28a) and (28b) are grammatical, since agreement is realized on the V-modal head in (28a) and on the complex DM V-head in (28b). Evidence that the agreement feature is carried only on the V-modal could in (28a) comes from the fact that the non-past P-modal may occurs here. In (28b), the entire complex V-head carries the agreement feature, spelled out as past-tense morphology on each modal constituent. In (28c), the P-modal displays past-tense marking, but there is no Vhead that agrees with the aspectual feature of 've, and so (28b) is ungrammatical. 
When the DM head undergoes overt $\mathrm{V} \rightarrow \mathrm{T}$ movement, it passes through AsPP. Here, the perfective morpheme 'vela may attach to the V-modal alone (29a), or to the complex DM head, in which case the affix is spelled out following each modal (29b). 've/a cannot attach to the P-modal alone (29c), as it is not a tensed V-head.

a. We might could've overlooked something.

b. He mighta should've gotten home by now.

c. * She mighta could done it.

The distribution of negation in a DMC follows the same pattern as aspect. In (6), repeated as (30), NEG heads a POLP between TP and VP, the DM passes through POLP, and NEG is realized on either the V-modal head (30a) or on the complex DM head, in which case it is spelled out following each modal (30b). While the adjunction-driven analysis accounts for (30a) and (30b), it incorrectly predicts ungrammaticality for (31), where negation follows the P-modal alone.

a. You might couldn't find it. [PoL [v [PoL might] [v couldn't ] $\left.\mathrm{POL}_{[\mathrm{NEG}]}^{0}\right]$

b. He might not couldn't refuse. [PoL [v [PoL might not] [v couldn't ] POL $\left._{[\mathrm{NEG}]}^{0}\right]$

... I might not could understand you.

[from $(6 \mathrm{c})]$

Section 5 will argue that (31) is derived from a distinct structure. For now, we turn our attention to interrogative DMCs.

Interrogative DMCs appear to be grammatical even without adjunction. In (32a), the failure of the P-modal might to undergo SAI along with the V-modal should indicates that might has not adjoined to should. This contrasts with (32b). Although the optionality of adjunction here may seem problematic for an adjunction-driven analysis, recall that adjunction serves only to allow the P-modal to get sentential scope, which it requires to carry out its function of modifying the truth conditions of the proposition. That is, it is the result (not the process) of adjunction that renders a DMC grammatical. However, since questions (unlike assertions) do not have truth conditions for P-modals to modify, the scope of a Pmodal in an interrogative DMC is irrelevant, making adjunction is unnecessary. However, optional adjunction may still occur, as in (32b) where the P-modal might undergoes SAI as part of the DM head. ${ }^{3}$ Finally, as predicted by our analysis, the P-modal cannot undergo SAI alone (33), as it is not a tensed V-head.

\footnotetext{
${ }^{3}$ Since (32b) involves PF movement that fulfills no requirements, it is less economical than (31a). This is reflected by acceptability judgments of native DM users (Battistella 1995), who prefer interrogative DMCs where adjunction does not occur (32a) over those in which it does (32b).
} 


\section{Minta Elsman and Stanley Dubinsky}

(32) a. Should we might cancel the trip?

[CP should $\mathbf{1}_{\text {[TP }}$ we $\mathbf{t}_{\mathbf{1}}$ [VP $\mathbf{t}_{\mathbf{1}}$ [POLP might [VP cancel ... ]]]]

b. Might can you do this later?

[CP [v might ${ }_{1}[\mathbf{v}$ can $\left.]\right]_{2}\left[\mathrm{TP}\right.$ you $\mathbf{t}_{\mathbf{2}}\left[\mathrm{VP}_{\mathbf{2}} \mathbf{t}_{\mathbf{2}}\left[\mathrm{POLP} \mathbf{t}_{\mathbf{1}}[\mathrm{vP}\right.\right.$ do $\left.\left.\left.\ldots]\right]\right]\right]$

*Might you could ...?

\section{One Construction, Two Analyses}

Recall our adjunction-driven analysis faces a problem in (6c) and (8b), repeated here. A constituent intervenes between the modals. In (6c), the V-modal is below negation, suggesting it has not moved from $\mathrm{V}$ to $\mathrm{T}$. In $(8 \mathrm{~b})$, the intervention of possibly between the P- and V- modals suggests the same, unless, quite improbably, the complex DM head contains an adverbial adjunct as a constituent.

c. I might not could understand you.

$$
\text { b. I've seen ones that might possibly could be flowers. [Di Paolo 1989] }
$$

To account for this, we posit that the two modals in $(6 c) /(8 b)$ are inserted in reverse order, with the $\mathrm{P}$-modal higher than the $\mathrm{V}$-modal, and that the untensed Vmodal stays in situ below NEG or the adverb, while the P-modal moves to $\mathrm{T}$ and then $\mathrm{C}$ at LF. (34) illustrates the LF representations of (6c) and (8b).

a. [CP might [ $_{1}$ I I $\mathbf{t}_{1}$ [POLP $\mathbf{t}_{1}$ [POLP not [VP could [VP understand you]]]]]

b. [CP might $_{1}$ [TP they $\mathbf{t}_{\mathbf{1}}$ [POLP $\mathbf{t}_{\mathbf{1}}$ [VP1 possibly [VP1 could [VP2 be flowers]]]]]

Although positing two distinct DMCs seems inefficient, it is justifiable from a variationist perspective. A comparison with Standard American English (SAE) suggests differing dialectal origins for the two DMCs seen here. The underlying representation of adjunction-driven DMC (35a) is non-Standard, in that a V-head selects POLP in violation of selectional restrictions of SAE, where only T selects POLP, and POL selects VP (Wilder 1997; Butler 2003), (36). ${ }^{4}$ In contrast, the selectional ordering of in-situ DMC (35b) mirrors that of SAE constructions (36):

a. We might should go in.

[Tе we T [vP should [PoLP might [vP go in ]]]]

b. I've seen ones that might possibly could be flowers.

[TP they [PoLP might [VP1 possibly [VP1 could [VP2 be flowers]]]]]

a. The children can't do that in there.

[TP the children [PoLP not [vP can [vP do that ... ]]]]]

\footnotetext{
${ }^{4}$ In some analyses of negation (Holmberg 2003) PolP selects TP. But regardless of the ordering of TP and PolP, no SAE analysis allows VP to select PolP, posited for adjunction-driven DMC.
} 
b. They might possibly have been flowers.

[TP they [PoLP might $\mathbf{1}_{1}$ [VP1 possibly [vP1 have [VP2 been flowers]]]]]

While the in-situ DMC bears a close structural resemblance to the SAE SMC, its regional distribution is matches that of adjunction-driven DMC. These facts suggest that the in-situ DMC is the result of attempts by SAE speakers to interpret and acquire the non-standard adjunction-driven DMCs they encountered within the constraints of SAE, which only allows POL to select VP, and not the reverse. A fuller discussion of this dialect contact hypothesis is found in Elsman (2007).

\section{Conclusion}

This paper has shown that a full explanation of the syntactic patterns exhibited in DMCs cannot be obtained by forcing such constructions into traditional (onemodal-per-clause) analyses of English modal auxiliaries. Instead, we have demonstrated that in order to account for the distribution of modals in DMCs, it is necessary examine the similarities between DM constructions and SM constructions, and in doing so, we have formulated an analysis that accounts for the syntactic properties of modals in both types of constructions.

\section{References}

Barbiers, Sjef. 2002. Current issues in modality: An introduction to modality and its interaction with the verbal system. In Sjef Barbiers, Frits Beukema, and Wim van der Wurff, eds., Modality and its interaction with the verbal system, 1-18. Philadelphia: John Benjamins.

Battistella, Edwin. 1995. The syntax of the double modal construction. Linguistica Atlantica 17:19-44.

Boertien, Harmon S. 1986. Constituent structure of double modals. In Michael Montgomery and Guy Bailey, eds., Language variety in the South: Perspectives in black and white, 294-318. Tuscaloosa: University of Alabama Press.

Brewer, Nicola M. 1989. Modality and factivity: One perspective on the meaning of the English modal auxiliaries. Ph.D. diss., University of Leeds.

Butler, Jonny. 2003. A minimalist treatment of modality. Lingua 113:967-996.

Cinque, Guglielmo. 1999. Adverbs and functional heads: A cross-linguistic perspective. Oxford: Oxford University Press.

Close, Joanne. 2004. English auxiliaires: A syntactic study of contraction and variation. Ph.D. diss., University of York.

Cormack, Annabel, and Neil Smith. 2002. Modals and negation in English. In Sjef Barbiers, Frits Beukema, and Wim van der Wurff, eds., Modality and its interaction with the verbal system, 133-163. Amsterdam: John Benjamins.

Davis, Steven, and Brendan S. Gillon. Linguistics and logic. In S. Davis and B. S. Gillon, eds., Semantics: A reader, 22-68. New York: Oxford University Press. 


\section{Minta Elsman and Stanley Dubinsky}

Di Paolo, Marianna. 1986. A study of double modals in Texas English. Ph.D. diss., University of Texas.

Di Paolo, Marianna. 1989. Double modals as single lexical items. American Speech 64:195-244.

Ellison, Gregory Campbell. 2007. You might shouldn't say that: The cartographic syntax of English multiple modal constructions and its (speculative) history. Generative Grammar in Geneva 5:51-106.

Elsman, Minta. 2007. The syntax of single and double modal constructions. Masters thesis, University of South Carolina.

Holmberg, Anders. 2003. Yes/no questions and the relation between tense and polarity in English and Finnish. Linguistic Variation Yearbook 3:43-68. Amsterdam: John Benjamins.

Kayne, Richard S. 2000. The English complementizer of. In Richard S. Kayne, Parameters and universals, 212-221. New York: Oxford University Press.

Marrano, Ann Marie. 1998. The syntax of modality: A comparative study of epistemic and root modal verbs in Spanish and English. Ph.D. diss., Georgetown University.

McDowell, Joyce. 1987. Assertion and modality. Ph.D. diss., University of Southern California.

Mishoe, Margaret. 1991. An analysis of the sociopragmatics of multiple modal use in sections of North and South Carolina. Masters thesis, University of South Carolina.

Mufwene, Salikoko S. 1994. Double modals in American Southern English: How peculiar are they? Contemporary Linguistics 1:89-104. University of Chicago.

Nagle, Stephen. 1994. The English double modal conspiracy. Diachronica 11:199-212.

Travis, Lisa. 1984. Parameters and effects of word order variation. Ph.D. diss., MIT.

Turner, Kathleen. 1981. A unified description of the systematic nature of double modals. Masters thesis, University of Alabama.

Van Gelderen, Elly. 2003. Asp(ect) in English modal complements. Studia Linguistica 57:27-43.

Wilder, Chris. 1997. English finite auxiliaries in syntax and phonology. In J. R. Black and V. Motapanyane, eds., Clitics, pronouns, and movement, 321-362. Amsterdam: John Benjamins.

Minta Elsman \& Stanley Dubinsky

Linguistics Program

University of South Carolina

Columbia, SC 29208

elsman@mailbox.sc.edu

dubinsky@sc.edu 